\title{
Participação Feminina na Produção Científica em Contabilidade Publicada nos Anais dos Eventos Enanpad, Congresso USP de Controladoria e Contabilidade e Congresso Anpcont
}

\section{Female Participation in the Scientific Production of Applied Accountancy in the Annals of the Enanpad events, USP Congress of Controllership and Accountancy and Anpcont Congress}

\author{
aḾrcia Martins Mendes De Luca; ${ }^{b}$ Carlos Adriano Santos Gomes;

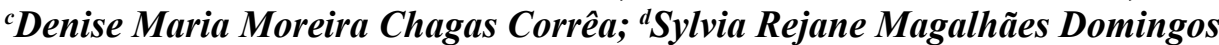 \\ ${ }^{a}$ Professora da Universidade Federal do Ceará, UFC; Doutorado em Controladoria e Contabilidade pela \\ Universidade de São Paulo, USP; Fortaleza, CE - Brasil; E-mail: marciadeluca@ufc.br \\ ${ }^{b}$ Professor da Universidade Federal do Ceará, UFC; Mestrado em Ciências Contábeis pelo \\ Centro de Pós Graduação e Pesquisa da Fundação Visconde de Cairu; Fortaleza, CE - Brasil; E-mail: contabeisfeaac@yahoo.com.br \\ 'Professora da Universidade Federal do Ceará, UFC; Doutorado em andamento em Educação pela \\ Universidade Federal do Ceará, UFC; Mestrado em Controladoria e Contabilidade pela Universidade de São Paulo, USP; \\ Fortaleza, CE-Brasil; E-mail: denisecorrea@secrel.com.br \\ ${ }^{d}$ Graduação em andamento em Ciências Contábeis pela Universidade Federal do Ceará \\ UFC ;Fortaleza,CE-Brasil; E-mail: sylvia_rejane@hotmail.com
}

\section{Resumo}

O estudo analisa a participação feminina na produção científica em contabilidade publicada nos anais dos Encontros da Associação Nacional de Pós-graduação e Pesquisa em Administração (EnANPAD), dos Congressos USP de Controladoria e Contabilidade e da Associação Nacional dos Programas de Pós-graduação em Ciências Contábeis (ANPCONT). Utilizou-se pesquisa documental, com enfoque bibliométrico na Lei de Lotka (BUFREM; PRATES, 2005), baseada nos anais dos eventos. Dentre os 1.294 artigos analisados nos anais da ANPAD e da USP (2004 a 2009) e da ANPCONT (2007 a 2009), verificou-se a participação feminina em 755 artigos, compreendendo 97 de autoria exclusivamente feminina e 658 de autoria mista (homens e mulheres). Constatou-se que a participação feminina na produção científica contábil, é significativamente pequena em relação à do gênero masculino, e que sua evolução relativa costuma acompanhar a da quantidade total de autores, sendo que nos últimos anos assinalou uma queda no tocante aos eventos da USP e da ANPAD, e um aumento no que tange ao da ANPCONT.

Palavras-chave: Produção científica feminina; Pesquisa contábil; Evento científico.

\section{Abstract}

The study analyzes female participation in the accounting scientific production in accountancy published in the annals of theon "Encontros da Associação Nacional de Pós-graduação e Pesquisa em Administração - EnANPAD", the "Congressos USP de Controladoria e Contabilidade" and the "Associação Nacional dos Programas de Pós-graduação em Ciências Contábeis" - ANPCONT" proceedings. Documental research was used with a bibliometrical focus in Lotka's Law (BUFREM; PRATES, 2005), based on the annals of the eventsevents 'proceedings. Among the 1.294 ANPAD and USP articles analyzed in the annals of the ANPAD and the USP events (from 2004 to 2009) and the ones of the ANPCONT events (from 2007 to 2009), female participation accounted for 755 articles, in which 97 were of exclusive female authorship and 658 of male/female authorship. The results point out that female participation in the accounting scientific production is significantly small regarding male participation and its evolution is usually indexed to the total number of authors. Furthermore, there has been a sharp fall in the USP and ANPAD events, and a rise in the ANPCONT events.

Keywords: Female Scientific Production; Accounting research; Scientific event. 
Participação Feminina na Produção Científica em Contabilidade Publicada nos Anais dos

Eventos Enanpad, Congresso USP de Controladoria e Contabilidade e Congresso Anpcont 146

\section{INTRODUÇÃ̃O}

Especialmente na última década, tem-se observado um crescimento na produção científica contábil brasileira, sobretudo aquela evidenciada por meio de canais de comunicação científica, compreendendo periódicos especializados e congressos acadêmicos.

Dentre os fatores que podem explicar esse crescimento, destacam-se o incremento no número de cursos de pós-graduação stricto sensu; o aumento do número de professores com dedicação exclusiva, especialmente nas instituições públicas; o estabelecimento de metas de produtividade nos programas de mestrado e doutorado, por exigência da Coordenação de Aperfeiçoamento de Pessoal de Nível Superior (Capes); e a maior oferta de bolsas de pesquisa e iniciação científica na graduação e na pós-graduação.

Observa-se também, como fenômeno da contemporaneidade, um avanço nos debates sobre a participação e atuação da mulher no campo contábil. Esse fato pode ser ilustrado tomandose como exemplo os diversos eventos voltados para a mulher contabilista periodicamente realizados em diferentes partes do país, a exemplo do Encontro Nacional da Mulher Contabilista, organizado pelo Conselho Federal de Contabilidade (CFC), que em 2010 alcançou sua oitava edição.

Também em outros países vêm sendo promovidas ações de valorização da mulher no campo contábil. De acordo com Vigilante (2006), o The American Institute of Certified Public Accountants (AICPA), dos EUA, tem dedicado especial atenção à participação feminina desde 1989, quando criou um comitê de estratégias para tornar mais efetiva a participação da profissional contábil na indústria, no governo e na academia.

Especificamente no campo do mercado de trabalho da área contábil, conforme apontam os dados do CFC, entre 2004 e 2008 a participação feminina, no total de registros profissionais, cresceu de $34,04 \%$ para $36,91 \%$, enquanto a proporção masculina caiu de $65,96 \%$ para $63,09 \%$. Em 2009 as mulheres já somavam 149.667 contabilistas (CFC, 2009).

Cabe destacar que não se sabe ao certo se há relação direta entre o crescimento do número de mulheres atuando na área contábil, seja no mercado de trabalho seja no ambiente acadêmico, e o seu desempenho no campo científico da contabilidade, notadamente nas pesquisas que são apresentadas sob a forma de artigos em congressos científicos; todavia, tais dados não deixam de chamar a atenção, pela observação de que a classe contábil esteja se expandindo, sendo que o gênero feminino tem crescido a taxa mais elevada que a do masculino, com reflexo também no campo da pós-graduação, seja lato ou stricto sensu.

Vale ressaltar que a configuração das relações de gênero e de suas implicações ocorre também no campo da produção científica na sociedade brasileira. As investigações desenvolvidas por mulheres, sobretudo no domínio das ciências sociais e humanas, têm se consolidado cada vez mais, comparativamente aos períodos anteriores à década de 1960, marcados pelo reduzido número de mulheres, enquanto sujeitos de pesquisa (CHAMON, 2005).

Bruschini e Puppin (2004) ressalvam que embora muitas mulheres estejam ocupando novos e promissores espaços de trabalho e na ciência, com características bastante similares às dos postos historicamente ocupados pelos homens, elas permanecem submetidas a desigualdades relativas à remuneração, ascensão profissional ao status.

Ao analisar a produção de conhecimento nos últimos 300 anos, nota-se que a ciência é eminentemente masculina. Na visão de Hayashi et al. (2007), muitas mulheres foram, e 
continuam sendo excluídas da produção científica. Mesmo nos tempos atuais, quando as mulheres dominam numericamente alguns campos disciplinares, a imagem de cientista é associada aos homens (HAYASHI ET AL, 2007)

Diversos estudos (VELHO; LEON, 2003; LETA, 2003; SOARES, 2001; HAYASHI ET AL, 2007; BANDEIRA, 2008) atentam para o fato de que em determinadas áreas de conhecimento, embora maioria, as mulheres não ascendem academicamente com a mesma velocidade de seus colegas do gênero masculino.

Diante dos mencionados aspectos, a questão objeto de investigação nesta pesquisa pode ser descrita da seguinte maneira: Qual a participação feminina na produção científica em contabilidade publicada nos anais das edições do Encontro da ANPAD, do Congresso USP de Controladoria e Contabilidade e do Congresso da ANPCONT?

O presente estudo tem como principal objetivo analisar a participação das mulheres na produção científica em contabilidade publicada em congressos que abordam a temática contábil, especificamente os eventos EnANPAD, USP de Controladoria e Contabilidade e ANPCONT.

Faz-se importante ressaltar que o volume de artigos publicados em periódicos e comunicados em congressos pode ser considerado como um dos critérios que revelam o nível de produtividade dos diversos campos da ciência, tais como as Ciências Contábeis. Analogamente, permite identificar também a efetiva contribuição das pesquisadoras femininas para a consolidação do corpus científico.

Dessa forma, este estudo se justifica na medida em que contribui para analisar o comportamento da produção científica da Contabilidade, em especial da participação feminina, por meio da investigação de aspectos como a localização geográfica dos autores, de forma que possa orientar futuros estudos sobre a diferença de gêneros no crescimento da produção dessa área do conhecimento.

O estudo exploratório quantitativo utiliza os procedimentos de pesquisa bibliográfica e documental, tendo sido coletados 1.294 artigos científicos publicados nos anais eletrônicos dos mencionados encontros. Fez-se uso do software SPSS ${ }^{\circledR}$ para aplicação de estatística descritiva, testes de correlação e comparação de médias e proporções alusivas à participação feminina na produção científica brasileira no campo contábil.

Além desta introdução, o estudo apresenta a revisão da literatura sobre o papel da mulher na sociedade, nas pesquisas científicas e nos eventos científicos; a metodologia utilizada na investigação; a análise dos resultados; e as conclusões da pesquisa.

\section{REFERENCIAL TEÓRICO}

\subsection{O papel da mulher na sociedade moderna}

O conflito de gêneros é algo que permeia a sociedade humana desde o início de sua existência. Durante séculos a mulher foi forçada a desempenhar papéis menos valorizados na escala de status (embora não menos importantes), como protetora do lar, responsável pelas atividades domésticas e tutora da prole.

Tietz (2007, p. 460) assinala que: 
a existência de barreiras sociais que criam a desigualdade para as mulheres surgiu historicamente a partir da tradicional divisão do trabalho. Antes do século XX, quando o trabalho era essencialmente de natureza física, as diferenças biológicas entre homens e mulheres deram origem a uma divisão de trabalho por gênero.

No tocante ao cenário brasileiro, Bruschini e Puppin(2004) entendem que fatores como transformações demográficas, culturais e sociais geraram grande impacto sobre o modo de vida da mulher, redundando em mudanças como a queda da taxa de fecundidade; o envelhecimento da população, com maior expectativa de vida das mulheres; e o aumento da proporção de famílias chefiadas por mulheres.

Mudanças nos padrões culturais e nos valores relativos ao papel social da mulher alteraram a identidade feminina, bem como a expansão da escolaridade e o ingresso nas universidades viabilizou o acesso dessas mulheres a novas oportunidades de trabalho. (BRUSCHINI; PUPPIN, 2004). O fator escolaridade também é apontado em pesquisa realizada por Blau (1997), para o período de 1970 e 1995, como razão para o aumento de cerca de $23 \%$ em termos absolutos da taxa de participação feminina na força de trabalho nos EUA, reduzindo de 45 para 16 pontos percentuais o diferencial de participação em relação aos homens.

Matos e Machado (2006) mostram que, desde 1979, as mulheres apresentam sistematicamente mais anos de estudo em relação aos homens. No entanto, o maior número médio de anos de escolaridade das mulheres, uma vez inseridas no mercado de trabalho, não se traduz necessariamente em remuneração média maior em relação à remuneração média recebida pelos homens (MACHADO; OLIVEIRA; WAJNMAN, 2005).

Vale ressaltar, conforme apontam Velho e Prochazka (2003), que, num primeiro momento, a proporção inferior de mulheres em posições de poder e destaque em muitos ramos de atividade tem sido frequentemente associada ao seu menor nível de escolaridade. Como corolário, seria de se esperar que, ao ter acesso à educação de maneira similar à dos homens, as mulheres passariam a partilhar com eles, proporcionalmente, tais posições de poder e destaque, inclusive aquelas do mundo das ciências.

\subsection{Participação da mulher no campo científico}

Na compreensão de Estébanez (2003), conhecer melhor a situação da mulher na ciência deve deixar de ser um discurso politicamente correto, para se tornar uma ação efetiva.

Para Soares (2001) a problemática que envolve a participação feminina no campo da ciência e tecnologia é o resultado de estruturas institucionais inapropriadas e não da inaptidão feminina para contribuir com essa área.

Ressalte-se que tal fenômeno não se restringe ao Brasil. Ao se examinar a lista dos 190 contemplados com o Prêmio Nobel de Física, desde 1901, quando foi criado, até 2010, são encontrados apenas dois nomes femininos. Por sua vez, em 41 edições do prêmio Nobel de Economia, apenas uma mulher foi vencedora. (DEC-UFCG, 2011).

Velho e Prochazka (2003) afirmam que, nas últimas décadas, tem-se observado significativo avanço da atuação feminina no campo da ciência e da tecnologia brasileiras, especialmente inseridas no âmbito das instituições de ensino superior e nos institutos de pesquisas.

Nesse sentido encontram-se na literatura investigações tais como as de Soares (2001) 
que pesquisou os entraves que limitam a ascensão feminina na ciência e tecnologia; Velho e Leon (2003) e Leta (2003) discutiram a construção social da produção científica por mulheres, o crescimento e os contrastes da participação feminina na ciência brasileira; Estebanez (2003), Velho e Prochazka (2003), Hayashi et al (2007) e Santos (2008) estudaram as dificuldades femininas na ascensão na carreira acadêmica; Bruschini e Puppin (2004) analisaram a presença de mulheres executivas em cargos de diretoria em empresas brasileiras. De modo análogo, Machado e Oliveira (2005) investigaram a inserção da mulher no mercado de trabalho brasileiro.

Dados demográficos recentes levam à constatação de crescimento ininterrupto da participação de mulheres no sistema de ciência e tecnologia (C\&T) brasileiro nos últimos trinta anos, notadamente nas instituições de ensino superior e de pesquisa (VELHO; PROCHAZKA, 2003; ROLEMBERG, 2001).

Velho e Prochazka (2003) fazem uma análise desse panorama na América Latina, afirmando:

Entre os matriculados na educação superior a participação dos gêneros é, no conjunto, equilibrada na região, talvez até mesmo mais favorável para as mulheres em países como Argentina, Uruguai e Brasil. Embora em algumas disciplinas técnicas e científicas, como ciências agrárias, engenharias e física, exista uma prevalência dos homens, as mulheres são maioria em química e biologia e, em alguns países, como Cuba, Costa Rica e Peru, até mesmo na medicina. Já nas ciências sociais, a proporção de mulheres é de cerca de $50 \%$ e nas ciências humanas, é superior a $60 \%$.

As evidências apontadas na citação anterior podem levar a entender que, em se verificando uma crescente presença do gênero feminino no campo da educação superior, é de se esperar que essa participação termine por influenciar também a presença da mulher na produção científica.

No Brasil, determinados indicadores podem ser reveladores do panorama da participação feminina na pesquisa. De acordo com dados do Conselho Nacional de Desenvolvimento Científico e Tecnológico - CNPQ (2011), no ano 2010 as mulheres foram majoritariamente beneficiadas com bolsas de iniciação científica $(53,65 \%)$, de mestrado $(52,41 \%)$ e doutorado $(50,7 \%)$. Contudo, relativamente às bolsas de produtividade científica a participação masculina ainda é predominante, considerando que apenas $34,87 \%$ de tais recursos foram contemplados para as pesquisadoras brasileiras. Nas Ciências Sociais Aplicadas, ao se considerar o total de bolsas concedidas pelo CNPQ, observa-se uma elevada concentração de recursos para os pesquisadores masculinos, uma vez que, de um total de 11.640 bolsas, 79,51\% foram a eles destinados, restando 20,49\% para as pesquisadoras femininas, ou seja, aproximadamente apenas 1 a cada 5 bolsas do CNPQ são direcionadas às mulheres (CNPQ, 2011).

Embora tais dados não sejam específicos da área contábil, mas de um campo macro na qual ela está inserida, é possível que exista uma similaridade desses indicadores com os números da participação feminina na evolução deste ramo do conhecimento.

Pesquisadoras femininas encontram obstáculos peculiares em sua trajetória acadêmica, dentre os quais, Soares (2001) destaca: a) dificuldade em conciliar as demandas da própria profissão e aquelas da profissão do parceiro; b) a sobrecarga devido ao acúmulo das tradicionais funções do lar e da profissão acadêmica; c) o reduzido número de mulheres em cargos de decisão; e d) o escasso reconhecimento dentro da própria comunidade científica.

Apesar dos obstáculos, esse cenário vem se alterando ao longo dos anos. Segundo Lopes (2003), há pouco mais de uma década, a participação das mulheres no sistema de ciência e tecnologia no país, na visão de diversos indicadores, oscilava consistentemente em torno 
de 30\%. Confirmando e aprofundando aspectos dessa tendência, em uma análise geral da participação das mulheres doutoras nas atividades de pesquisa, os dados indicam, em proporções aproximadas, que entre os que se titularam no país até 1965, para cada 6,3 homens, havia uma mulher titulada; no período de 1976 a 1980, para cada três homens, uma mulher se doutorava; entre 1986 e 1990 a proporção era de uma mulher para 1,8 homem; e entre 1996 e 2000 chega a quase uma para um.

Embora a citada pesquisa não apresente uma divisão estatística por área, é provável que esse comportamento também se manifeste no campo contábil, uma vez que a pesquisa do CFC (2009) apontou um crescimento no número de profissionais do gênero feminino ali registrado nos últimos anos.

Soares (2001) afirma que a baixa percentagem de mulheres em posições acadêmicas continua sendo um problema mundial. Sob o aspecto econômico, a reduzida proporção de mulheres em áreas científicas significa o desperdício de recursos humanos altamente qualificados que podem contribuir com soluções cientificamente criativas bem como com diferentes pontosde-vista. Sob o aspecto puramente científico, profissionais femininas contribuem para uma maior diversidade de abordagens e soluções para um dado problema.

De acordo com Velho e Leon (2003, p. 315), "esta menor produtividade das mulheres, no entanto, tem sido bastante relativizada em estudos que procuram entender os contextos, motivações e condições de produção de homens e mulheres na academia". Segundo esses autores, aspectos e conflitos como a relação família-trabalho e níveis de investimento na educação feminina influenciam essa produtividade.

De modo conclusivo, Santos (2008) pontua que dentre tantas dúvidas possíveis, uma coisa é certa: a necessidade de cada vez mais mulheres saírem do não-lugar na ciência. Para tanto, faz-se necessário o esforço de pesquisadoras e pesquisadores para aprofundar os estudos que situem a real condição feminina nesse campo.

\subsection{Os eventos científicos para a disseminação de pesquisas contábeis}

$\mathrm{Na}$ última década cresceu significativamente a produção acadêmico-científica no ramo do conhecimento contábil. Em decorrência disso, a cada ano são criados novos canais de disseminação desses estudos, especialmente os periódicos eletrônicos, eventos gerais e setoriais.

Entre os canais utilizados para comunicar o conhecimento científico, destacam-se aqueles que respeitam procedimentos rigorosos para efetivar a comunicação, envolvendo a avaliação dos pares e, de fato, constituindo uma maneira de formalizar o conhecimento produzido para os membros da comunidade científica. Seja um canal representado por periódico, livro, evento científico ou outro, é fundamental assegurar que a informação publicada seja confiável, bem como as novas colaborações correspondam ao pensamento da comunidade científica da área, a qual assume, por meio do processo de avaliação por pares, uma posição consensual quanto aos textos produzidos.

Vanti (2002, p. 152) ressalta a importância da avaliação neste contexto:

A avaliação, dentro de um determinado ramo do conhecimento, permite dignificar o saber quando métodos confiáveis e sistemáticos são utilizados para mostrar à sociedade como tal saber vem se desenvolvendo e de que forma tem contribuído para resolver os problemas que se apresentam dentro de sua área de abrangência. 
É possível afirmar que a publicação das pesquisas constitui um caminho necessário para o reconhecimento formal do investigador perante a comunidade científica, em quaisquer áreas de atuação, não sendo diferente no campo contábil.

Em observância aos aspectos mencionados, Santos (2008, p. 1) afirma que "a busca por prestígio e reconhecimento é algo inerente ao campo científico, tendo em vista a maneira como estrutura e é estruturado (...) e os pesquisadores e as pesquisadoras buscam publicar, o mais rápido possível suas pesquisas".

Nesse sentido, eventos científicos anuais, como os encontros da ANPAD, da ANPCONT e da USP, que constituem o foco deste estudo, catalisam e disseminam as diversas pesquisas quem vem sendo desenvolvidas nos mais variados pontos do país.

Promovido pela ANPAD, o EnANPAD possui, dentre outras, uma divisão científica de Contabilidade. O Congresso USP de Controladoria e Contabilidade é promovido pelo Departamento de Contabilidade e Atuária da Faculdade de Economia, Administração e Contabilidade da USP, e o Congresso ANPCONT é promovido pela Associação Nacional dos Programas de Pós-Graduação em Ciências Contábeis. Para a disseminação das pesquisas na área das ciências contábeis, esses são alguns dos principais eventos científicos que ocorrem anualmente no Brasil.

Como dado ilustrativo, em 2009, os mencionados eventos publicaram em seus anais um total de 239 artigos relacionados ao campo das ciências contábeis. Esse número extrapola a capacidade de disseminação dos periódicos científicos da área, que, por questões operacionais, acadêmicas, materiais e financeiras, apresentam uma limitação na quantidade de artigos publicados a cada ano.

Com o incremento na produção científica, surgem novos desafios e a necessidade de estudos a serem realizados para a compreensão de tal fenômeno. Nesse sentido, Oliveira et al $(2007$, p. 2) assinalam que "monitorar a produção científica em âmbito nacional é muito importante para avaliar o crescimento das diversas áreas do conhecimento". Nesse sentido, a investigação acerca das pessoas envolvidas no desenvolvimento das pesquisas também se mostra relevante, inclusive no tocante à participação feminina nos trabalhos publicados em eventos acadêmicos.

\subsection{Abordagens Bibliométricas na Pesquisa Contábil}

Nos últimos anos tem-se tornado frequente o desenvolvimento de pesquisas contábeis com enfoque bibliométrico; tal fato é decorrente do crescimento na quantidade de comunicações acadêmicas, especialmente sob a forma de artigos científicos. NoBrasil, esse fenômenotem relação direta com o avanço do número de programas de pós-graduação stricto sensu, e sua consequente influência na ampliação dos canais de comunicação, notadamente os eventos e revistas científicas.

O desenvolvimento de investigações científicas com enfoque bibliométrico no campo das Ciências Contábeis ocorreu inicialmente, com maior frequência, em nível internacional, entretanto, nos últimos anos tornou-se recorrente também no Brasil. Como exemplos de investigações podem-se citar as pesquisas elaboradas por Riccio, Carastan e Sakata (1999), ao analisaram teses e dissertações dos programas de pós-graduação stricto senso em contabilidade entre os anos de 1962 e 1999; Frezatti e Borba (2000), que efetuaram um estudo junto às revistas internacionais em língua inglesa que publicam temas relacionados à contabilidade; 
Oliveira (2001), que analisou os periódicos científicos nacionais em termos de conteúdo e forma; e Martins (2002), que efetuou um estudo específico dos artigos publicados num período de doze anos nos Cadernos de Estudos, publicado pela Universidade de São Paulo.

Braga, Cruz e Oliveira (2007, p. 2) afirmam que tal metodologia visa "medir quantitativamente determinados aspectos da produção científica". Para Saineiro (2008), a pesquisa bibliométrica se refere aos estudos da organização dos campos e fontes de informação. Guedes e Borshiver (2005, p. 02) afirmam ser esta "um conjunto de leis e princípios empíricos que contribuem para estabelecer os fundamentos teóricos da Ciência".

A importância das pesquisas com enfoque bibliométricos é ratificada por Machado (2007, p. 3), quando este explicita que "a atividade cientifica e tecnológica de um país requer um monitoramento, a fim de traçar-se seu estágio de desenvolvimento". Todavia, Campos (2003) alerta que os indicadores bibliométricos não devem ser confundidos com definidores de qualidade, embora sejam úteis enquanto indicadores de desempenho para avaliar a pesquisa acadêmica.

Alvarenga (1998) avalia que os resultados de estudos bibliométricos, no que tange especialmente à quantificação da literatura publicada e ao mapeamento da rede de relações estabelecida entre autores e textos, podem se constituir em insumos empíricos da maior importância para que se evidenciem ângulos peculiares do processo de produção de conhecimentos, ensejando o desenvolvimento de posteriores análises de natureza qualitativa.

De acordo com Bufrem e Prates (2005), em geral, as leis bibliométricas mais comumente utilizadas nessa metodologia são aquelas relacionadas à produtividade científica (Lei de Lotka), à dispersão da produção científica (Lei de Bradford) e à ocorrência de palavras no texto(Lei de Zipf).

Para fins deste estudo, adota-se um enfoque lotkaniano, uma vez que a pesquisa procura identificar por meio da contagem completa, os autores de uma determinada amostra de artigos científicos de modo a identificar a participação feminina na produção científica contábil brasileira. Sobre tal enfoque, Alvarado (2002) afirma que na contagem completa, diferente das contagens direta e ajustada, cada autor (principal e/o secundário) é creditado com uma contribuição, isto é, não existe distinção de grau de importância entre autores e co-autores. Tal método de contagem é coerente com a proposta deste estudo, uma vez que a fonte de dados utilizada não especifica grau de hierarquia entre os articulistas.

\section{METODOLOGIA}

Durante a pesquisa exploratória, o contato com o tema relacionado à participação feminina no mundo dos negócios e da academia serviu de base de inspiração para realização do estudo. Assim, por meio de levantamento bibliográfico, foram avaliados os papeis da mulher na sociedade moderna e no campo científico, assim como a importância dos eventos científicos para o desenvolvimento da ciência contábil.

Esta pesquisa utiliza informações obtidas a partir de fontes públicas divulgadas nos anais dos três citados grupos de eventos: EnANPAD, USP de Controladoria e Contabilidade e ANPCONT. O estudo constitui uma pesquisa documental, com enfoque bibliométrico na Lei de Lotka (BUFREM; PRATES, 2005), baseada nos anais dos mencionados congressos, voltada para a investigação, principalmente, dos autores dos artigos publicados, com destaque especial para a participação feminina. 
No que tange aos procedimentos para viabilização do estudo, optou-se por desenvolvêlo em três etapas. A primeira delas concentrou-se na construção do marco teórico; na segunda, procedeu-se à catalogação dos artigos relativos à temática contábil junto aos anais dos encontros selecionados; e na terceira, realizou-se o tratamento estatístico dos dados levantados, seguido de sua análise.

A coleta dos dados se deu por meio de um instrumento estruturado de maneira a identificar os seguintes elementos: evento, ano, título, área temática, autor, gênero, instituição e procedência. Foram coletados 1.294 artigos, dos três eventos selecionados, publicados nos seguintes períodos: EnANPAD e USP - 2004 a 2009 e ANPCONT - 2007 a 2009. O ano 2004 foi escolhido como marco inicial da coleta, por ter sido o primeiro em que o evento da USP se configurou como congresso. O primeiro Congresso ANPCONT ocorreria em 2007.

Ressalta-se que do evento EnANPAD foram coletados apenas os artigos relativos à temática contábil. Assim, fizeram parte da coleta os artigos apresentados nas áreas e divisões acadêmicas relacionadas à contabilidade no período de 2004 a 2009. Da área de Ensino e Pesquisa em Administração e Contabilidade, do ano 2004, foram considerados apenas os artigos relacionados à área contábil.

Após a catalogação dos artigos, procedeu-se ao tratamento dos dados, realizando-se estatísticas descritivas, testes de correlação e comparação de médias e proporções. Os cálculos e testes estatísticos foram desenvolvidos com auxílio do SPSS ${ }^{\circledR}$, adotando-se o nível de significância 0,05 . As tabelas e os gráficos resultantes dos estudos e dos testes realizados, bem como sua análise, são apresentados na seção seguinte.

\section{RESULTADOS DA PESQUISA}

A primeira análise dos dados gerais coletados nos anais dos eventos selecionados foi organizada de forma a identificar a quantidade de artigos com a participação exclusiva de mulheres, bem como a participação exclusiva de homens, além do número de artigos de autoria de homens e mulheres, distribuídos por região geográfica (Tabela 1).

Tabela 1 - Artigos por região no período 2004-2009 (EnANPAD, USP e ANPCONT)

\begin{tabular}{c|c|c|c|c|c|c|c|c}
\hline \multirow{2}{*}{ Região } & \multicolumn{2}{|c|}{$\begin{array}{c}\text { Artigo apenas com } \\
\text { mulheres }\end{array}$} & \multicolumn{2}{c|}{$\begin{array}{c}\text { Artigo apenas com } \\
\text { homens }\end{array}$} & \multicolumn{2}{c|}{ Artigos mistos } & \multicolumn{3}{c}{ Total } \\
\cline { 2 - 10 } & Qtde. & $\%$ & Qtde. & $\%$ & Qtde. & $\%$ & Qtde. & $\%$ \\
\hline Sudeste & 45 & 46.4 & 314 & 58.3 & 299 & 45.4 & 658 & 50.9 \\
\hline Nordeste & 17 & 17.5 & 78 & 14.5 & 127 & 19.3 & 222 & 17.2 \\
\hline Sul & 29 & 29.9 & 110 & 20.4 & 169 & 25.7 & 308 & 23.8 \\
\hline Centro-Oeste & 1 & 1 & 27 & 5 & 38 & 5.8 & 66 & 5.1 \\
\hline Norte & 0 & 0 & 2 & 0.4 & 5 & 0.8 & 7 & 0.5 \\
\hline Exterior & 5 & 5.2 & 8 & 1.5 & 20 & 3 & 33 & 2.6 \\
\hline Total & 97 & 100 & 539 & 100 & 658 & 100 & 1294 & 100 \\
\hline
\end{tabular}

Fonte: Dados da pesquisa (2009).

A Tabela 1 evidencia que, dos 755 artigos publicados com a participação de mulheres, 
quase metade (45,5\%) origina-se da região Sudeste, seguida da região Sul (26,2\%). Observouse também que mais da metade dos artigos (50,9\%) tem autoria mista. Tais resultados podem estar relacionados ao fato de essas duas regiões concentrarem maior quantidade de cursos de mestrado e doutorado no campo contábil e em áreas afins.

\subsection{Participação das mulheres nos eventos da ANPAD, da USP e da ANPCONT}

A evolução da participação feminina nos artigos em cada um dos grupos de eventos é apresentada a seguir. O Gráfico 1 possibilita uma comparação entre a participação das mulheres e o total de autores nas cinco últimas edições anuais dos eventos da ANPAD.

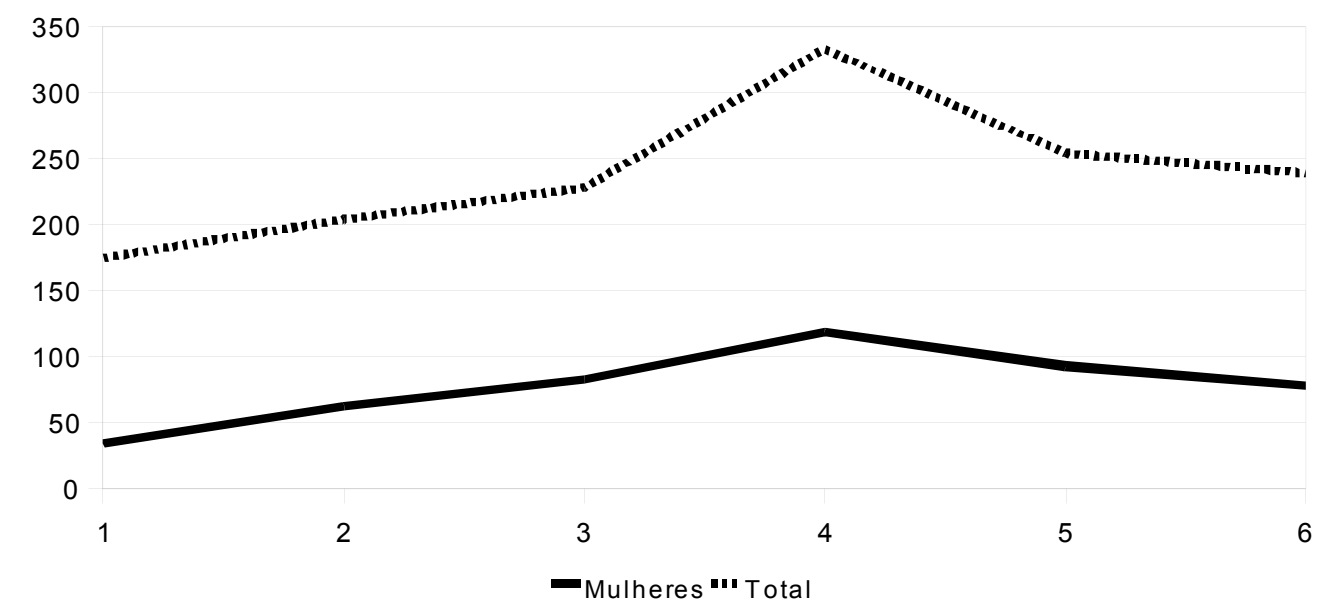

Gráfico 1 - Quantidade de mulheres no EnANPAD - 2004-2009

Fonte: Dados da pesquisa (2009).

O Gráfico 1 evidencia que o comportamento do gênero feminino assemelha-se ao do total de autores participantes do evento, como pode ser observado, por exemplo, na edição de 2007, quando ocorreu elevação na quantidade total de autores, como também de autoras, em proporção semelhante.

A Tabela 2 apresenta a evolução da proporção das mulheres em relação ao total de autores de artigos publicados no EnANPAD, no período de 2004 a 2009.

Tabela 2 - Descritiva da proporção de mulheres nos artigos do EnANPAD

\begin{tabular}{c|c|c|c}
\hline Ano & $\mathrm{N}$ & Média & Desvio Padrão \\
\hline 2004 & 76 & 0,18 & 0,26 \\
\hline 2005 & 81 & 0,30 & 0,33 \\
\hline 2006 & 88 & 0,36 & 0,35 \\
\hline 2007 & 111 & 0,35 & 0,30 \\
\hline 2008 & 88 & 0,34 & 0,30 \\
\hline 2009 & 81 & 0,32 & 0,31 \\
\hline
\end{tabular}

Fonte: Dados da pesquisa (2009).

Analisando-se a Tabela 2, pode-se notar que houve um significativo aumento na participação da quantidade de mulheres nos artigos publicados no EnANPAD entre 2004 e 
2007. Em contrapartida, entre 2007 e 2009 essa participação decresce, embora a uma taxa mais baixa.

A análise de variância, na qual se testa a hipótese de que não há diferença entre as médias das proporções, possibilitou concluir que tais diferenças são estatisticamente significativas $(\mathrm{p}<0,05)$, de acordo com a Tabela 3 .

Tabela 3 - Análise de Variância - ANOVA para os anos - Evento EnANPAD

\begin{tabular}{c|c|c|cc|c}
\hline ANOVA & Soma de quadrados & Gl & Quadrado médio & F & P-valor \\
\hline Between Groups & 1,739 & 5 & 0,348 & 3,599 & 0,003 \\
\hline Within Groups & 50,144 & 519 & 0,097 & & \\
\hline Total & 51,883 & 524 & & & \\
\hline
\end{tabular}

Fonte: Dados da pesquisa (2009).

Diante desse resultado, rejeita-se a hipótese de que as médias de proporções da quantidade de mulheres são todas iguais, ou seja, é razoável aceitar a hipótese de que há pelo menos uma média diferente das demais. Dada essa constatação, realizou-se o teste post hoc (comparações múltiplas - que testam as diferenças de médias duas a duas), indicando que as diferenças ocorrem entre as proporções do ano 2004 com as dos anos 2006, 2007 e 2008, sendo a proporção de 2004 significativamente inferior à desses outros anos.

De modo análogo, o Gráfico 2 apresenta a participação feminina no Congresso USP de Controladoria e Contabilidade, no período de 2004 a 2009, assim como o total de autores do evento.

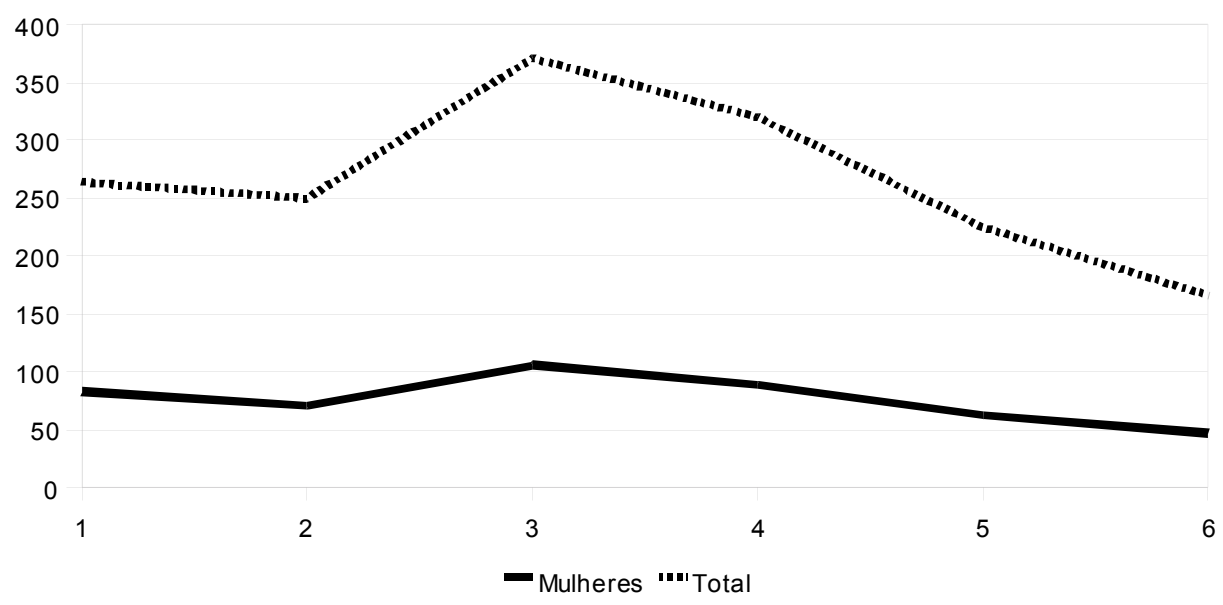

Gráfico 2 - Quantidade de mulheres no Congresso USP - 2004-2009

Fonte: Dados da pesquisa (2009).

Assim como ocorreu com os artigos do EnANPAD, no Congresso USP observa-se também um comportamento da participação feminina semelhante ao do total dos autores, muito embora se tenha notado um crescimento menos acentuado da presença de pesquisadoras no intercurso das edições de 2005 e 2006, em comparação com o total de autores, por exemplo.

Numa análise das médias e desvios-padrão da proporção de mulheres em relação à quantidade de autores nos artigos publicados no Congresso USP (Tabela 4), nota-se que, a partir de 2005, há um crescimento nessa proporção, ou seja, verifica-se um contínuo aumento, apesar de discreto, na proporção de autoras dos trabalhos publicados. Ressalta-se ainda que os 
Participação Feminina na Produção Científica em Contabilidade Publicada nos Anais dos

Eventos Enanpad, Congresso USP de Controladoria e Contabilidade e Congresso Anpcont 156

desvios-padrão parecem não variar ano a ano.

Tabela 4 - Descritiva da proporção de mulheres nos artigos do Congresso USP

\begin{tabular}{c|c|c|c}
\hline Ano & N & Média & Desvio Padrão \\
\hline 2004 & 98 & 0,29 & 0,32 \\
\hline 2005 & 98 & 0,26 & 0,32 \\
\hline 2006 & 150 & 0,27 & 0,31 \\
\hline 2007 & 117 & 0,27 & 0,28 \\
\hline 2008 & 79 & 0,29 & 0,31 \\
\hline 2009 & 63 & 0,30 & 0,32 \\
\hline
\end{tabular}

Fonte: Dados da pesquisa (2009).

Após a aplicação do teste de análise de variância das médias da proporção de autoras nos artigos, para verificar se as proporções diferiam significativamente ao longo dos anos, constatou-se um pequeno crescimento nessas medidas.

A Tabela 5 mostra que a análise de variância, a qual testa a hipótese de que não há diferença nas médias das proporções, possibilitou a conclusão de que tais diferenças não são estatisticamente significativas $(p>0,05)$, ou seja, as médias anuais podem ser consideradas estatisticamente iguais.

Tabela 5 - Análise de Variância - ANOVA para os anos - Congresso USP

\begin{tabular}{c|c|c|c|c|c}
\hline ANOVA & Soma de quadrados & Gl & Quadrado médio & F & P-valor \\
\hline Between Groups & 0,137 & 5 & 0,027 & 0,289 & 0,919 \\
\hline Within Groups & 56,905 & 599 & 0,095 & & \\
\hline Total & 57,043 & 604 & & & \\
\hline
\end{tabular}

Fonte: Dados da pesquisa (2009).

O Gráfico 3 possibilita uma comparação entre a participação feminina e o total de autores no Congresso da ANPCONT, em suas três edições anuais do período de 2007 a 2009.

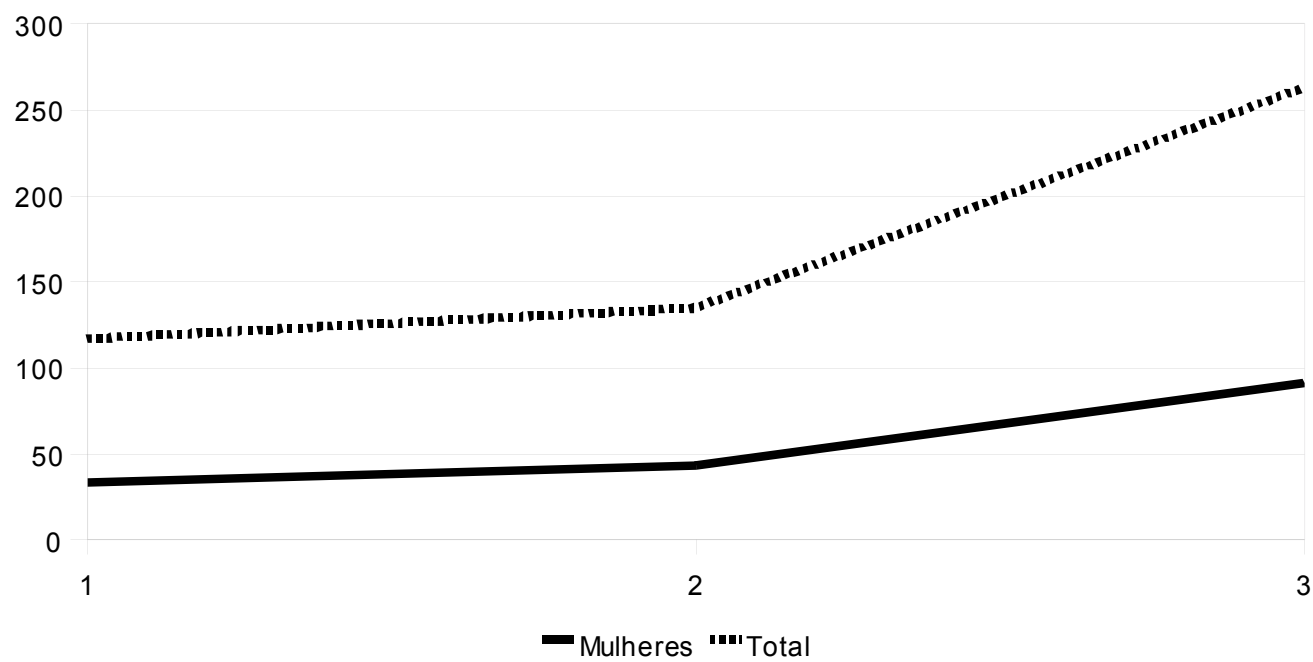

Gráfico 3 - Quantidade de mulheres no ANPCONT - 2007-2009

Fonte: Dados da pesquisa (2009).

Do mesmo modo que nos demais eventos, também nas edições do Congresso da 
ANPCONT a participação feminina assinala evolução semelhante à do total de autores; a diferença é que, diferentemente do que ocorre nos eventos da ANPAD e da USP, a participação no Congresso da ANPCONT é sempre crescente. Vale ressaltar, contudo, que até o momento de realização desta pesquisa a ANPCONT promoveu apenas três edições do seu congresso para o período analisado (2007 a 2009).

A Tabela 6, a seguir, mostra as médias e desvios-padrão da proporção de mulheres em relação à quantidade de autores nos artigos publicados no Congresso da ANPCONT, no período analisado.

Tabela 6 - Descritiva da proporção de mulheres nos artigos do Congresso da ANPCONT

\begin{tabular}{c|c|c|c}
\hline Ano & N & Média & Desvio Padrão \\
\hline 2007 & 47 & 0,29 & 0,34 \\
\hline 2008 & 47 & 0,31 & 0,33 \\
\hline 2009 & 97 & 0,34 & 0,32 \\
\hline \multicolumn{2}{c}{ Fonte: Dados da pesquisa (2009). }
\end{tabular}

Os resultados apontam para um crescimento nessa proporção, ou seja, verifica-se um contínuo crescimento na quantidade de autoras dos trabalhos. Ademais, os desvios-padrão (em torno de 0,34 ) revelam uma grande dispersão nos dados (aproximadamente $117 \%$ do valor de sua média em 2007, por exemplo). Na Tabela 7, efetua-se uma análise de variância para as edições do Congresso da ANPCONT.

Tabela 7 - Análise de Variância - ANOVA para os anos - Congresso da ANPCONT

\begin{tabular}{c|c|c|c|c|c}
\hline ANOVA & Soma de quadrados & Gl & Quadrado médio & F & P-valor \\
\hline Between Groups & 0,077363 & 2 & 0,038681 & 0,343 & 0,710 \\
\hline Within Groups & 21,19691 & 188 & 0,11275 & & \\
\hline Total & 21,27428 & 190 & & & \\
\hline \multicolumn{5}{r}{ Fonte: Dados da pesquisa (2009). }
\end{tabular}

A análise de variância realizada para as edições do Congresso daANPCONT possibilitou a conclusão de que as diferenças nas médias das proporções não são estatisticamente significativas $(\mathrm{p}>0,05)$. Assim sendo, pode-se considerar as médias dos anos estatisticamente iguais. Esse fato pode ser explicado devido à grande variabilidade nos dados da amostra do citado evento.

\subsection{Teste de correlação e comparação de médias de participantes nas edições do Encontro da ANPAD do Congresso USP e do Congresso da ANPCONT}

Antes de se realizar o teste de correlação, fez-se necessário saber se a distribuição dos dados seguiu uma distribuição normal. Referido procedimento foi necessário ainda para a escolha do tipo de correlação que seria aplicada neste estudo (correlação de Pearson).

Assim, foram realizados os testes de normalidade (teste Kolmogorov-Smirnov) para a quantidade de mulheres nos períodos analisados. No evento EnANPAD, para todos os tipos de participação (homens e mulheres), observou-se p-valor $>0,05$, aceitando-se a hipótese nula, que supõe que os dados se originam de uma população normal. Os resultados do evento USP, para homens e mulheres, também indicaram p-valor $>0,05$, podendo-se inferir que os dados são de uma população normal. Referido teste não foi realizado para o Congresso da ANPCONT isoladamente, tendo em vista que a observação de apenas três anos (quantidade de eventos) poderia distorcer os resultados. 
Participação Feminina na Produção Científica em Contabilidade Publicada nos Anais dos

Eventos Enanpad, Congresso USP de Controladoria e Contabilidade e Congresso Anpcont 158

A Tabela 8 apresenta o teste de normalidade, considerando toda a população analisada, ou seja, homens e mulheres dos três grupos de eventos: EnANPAD, USP e ANPCONT. O resultado mostra $\mathrm{p}$-valor $>0,05$, podendo-se inferir que os dados são de uma população normal.

Tabela 8 - Teste de normalidade para a quantidade de participantes no período nos três grupos de eventos

\begin{tabular}{c|c|c|c}
\hline \multirow{2}{*}{ Geral } & \multicolumn{3}{|c}{ Kolmogorov-Smirnov } \\
\cline { 2 - 4 } & Estatística & Gl & P-valor \\
\hline Mulheres & 0,117 & 15 & 0,200 \\
\hline Homens & 0,157 & 15 & 0,200 \\
\hline Total & 0,148 & 15 & 0,200 \\
\hline
\end{tabular}

Fonte: Dados da pesquisa (2009).

Para analisar as relações entre as quantidades de autores ao longo dos anos, utilizou-se o teste de correlação, ou seja, mediu-se a correlação entre as variáveis, observando-se a variação ano a ano.

O teste de correlação (correlação de Pearson) realizado para o EnANPAD indicou uma forte correlação entre a quantidade de participantes do gênero feminino e as quantidades de participantes do gênero masculino e total, embora apenas a correlação com a quantidade de participantes do gênero masculino tenha sido significativa $(\mathrm{p}<0,05)$. Por sua vez, a participação dos homens possui correlação bastante significativa com o total de participantes, provavelmente devido à grande quantidade de autores do gênero masculino nos eventos (Tabela 9).

Tabela 9 - Teste de correlação entre as quantidades de participantes no período - EnANPAD

\begin{tabular}{|c|c|c|c|c|}
\hline \multicolumn{2}{|r|}{ Enanpad } & Mulheres & Homens & Total \\
\hline \multirow{3}{*}{ Mulheres } & Correlação de Pearson & \multirow{3}{*}{-} & $0,832 *$ & $0,956^{*}$ \\
\hline & P-valor & & 0,044 & 0,644 \\
\hline & $\mathrm{N}$ & & 6 & 6 \\
\hline \multirow{3}{*}{ Homens } & Correlação de Pearson & $0,832 *$ & & $0,954 *$ \\
\hline & P-valor & 0,044 & - & 0,003 \\
\hline & $\mathrm{N}$ & 6 & & 6 \\
\hline \multirow{3}{*}{ Total } & Correlação de Pearson & $0,956^{*}$ & $0,954 *$ & \multirow{3}{*}{ - } \\
\hline & P-valor & 0,644 & 0,003 & \\
\hline & $\mathrm{N}$ & 6 & 6 & \\
\hline
\end{tabular}

Adicionalmente, foi realizado o teste $t$ de Student, para comparar as médias de participantes no período. A Tabela 10 registra que o teste realizado para o EnANPAD indica que, além de grande, a diferença das médias é significativa ( $p$-valor $<0,05$ ). Os homens participaram, em média, de modo mais intenso do que as mulheres nos eventos da ANPAD.

Tabela 10 - Teste t de Student para comparar as médias de participantes no período - EnANPAD

\begin{tabular}{c|c|c|c|c|c|c}
\hline Enanpad & Média & N & Desvio Padrão & $T$ & gl & P-valor \\
\hline Mulheres & 78,33 & 6 & 28,605 & \multirow{2}{*}{$-5,05$} & \multirow{2}{*}{10} & 0,001 \\
\hline Homens & 160,5 & 6 & 27,797 & & & \\
\hline
\end{tabular}

Fonte: Dados da pesquisa (2009).

Para o Congresso USP, o resultado do teste de correlação entre os participantes no período de 2004 a 2009 está apresentado na Tabela 11. 
Tabela 11 - Teste de correlação entre os participantes no período - Congresso USP

\begin{tabular}{|c|c|c|c|c|}
\hline & USP & Mulheres & Homens & Total \\
\hline \multirow{3}{*}{ Mulheres } & Correlação de Pearson & \multirow{3}{*}{ - } & $0,971 *$ & $0,985 *$ \\
\hline & P-valor & & 0,001 & 0,000 \\
\hline & $\mathrm{N}$ & & 6 & 6 \\
\hline \multirow{3}{*}{ Homens } & Correlação de Pearson & $0,971^{*}$ & & $0,998 *$ \\
\hline & P-valor & 0,001 & - & 0,000 \\
\hline & $\mathrm{N}$ & 6 & & 6 \\
\hline \multirow{3}{*}{ Total } & Correlação de Pearson & $0,985^{*}$ & $0,986^{*}$ & \multirow{3}{*}{ - } \\
\hline & P-valor & 0,000 & 0,000 & \\
\hline & $\mathrm{N}$ & 6 & 6 & \\
\hline
\end{tabular}

Todas as correlações calculadas são positivas e superiores a 0,5 , sendo consideradas fortes e significantes ( $p$-valor $>0,05$ ), ou seja, à medida que uma quantidade de artigos aumenta de um ano para o outro, a outra quantidade de artigos correlacionada também aumenta.

O teste $t$ de Student, que compara as médias de participantes no período de 2004 a 2009 do Congresso USP, indicou, conforme mostra a Tabela 12, uma grande e significativa diferença entre as participações masculina e feminina, evidenciando comportamento semelhante ao apresentado no EnANPAD para o mesmo período, ou seja, homens participando mais do que as mulheres.

Tabela 12 - Teste t de Student para comparar as médias de participantes no período - Congresso USP

\begin{tabular}{c|c|c|c|c|c|c}
\hline USP & Média & N & Desvio Padrão & $T$ & gl & P-valor \\
\cline { 1 - 4 } Mulheres & 76,5 & 6 & 20,744 & \multirow{2}{*}{$-4,97$} & \multirow{2}{*}{10} & \multirow{2}{*}{0,001} \\
\cline { 1 - 4 } Homens & 189,5 & 6 & 51,636 & & & \\
\hline \multicolumn{7}{c}{ Fonte: Dados da pesquisa (2009). }
\end{tabular}

Considerando apenas três observações (anos 2007, 2008 e 2009) do Congresso da ANPCONT, não foram realizados os cálculos estatísticos (correlação e teste de médias), da forma como realizado para os outros dois grupos de eventos científicos.

Os resultados dos testes de correlação e de médias para os três grupos de eventos, em conjunto, estão apresentados nas Tabelas 13 e 14 e confirmam os resultados encontrados isoladamente para os eventos da ANPAD e da USP.

Tabela 13 - Teste de correlação entre os participantes no período dos três grupos de eventos

\begin{tabular}{|c|c|c|c|c|}
\hline \multicolumn{2}{|r|}{ Geral } & Mulheres & Homens & Total \\
\hline \multirow{3}{*}{ Mulheres } & Correlação de Pearson & \multirow{3}{*}{ - } & $0,824 *$ & $0,923 *$ \\
\hline & P-valor & & 0,000 & 0,000 \\
\hline & $\mathrm{N}$ & & 15 & 15 \\
\hline \multirow{3}{*}{ Homens } & Correlação de Pearson & $0,824^{*}$ & & $0,979 *$ \\
\hline & P-valor & 0,000 & - & 0,000 \\
\hline & $\mathrm{N}$ & 15 & & 15 \\
\hline \multirow{3}{*}{ Total } & Correlação de Pearson & $0,923^{*}$ & $0,979^{*}$ & \multirow{3}{*}{-} \\
\hline & P-valor & 0,000 & 0,000 & \\
\hline & $\mathrm{N}$ & 15 & 15 & \\
\hline
\end{tabular}

Fonte: Dados da pesquisa (2009). 
Participação Feminina na Produção Científica em Contabilidade Publicada nos Anais dos

Eventos Enanpad, Congresso USP de Controladoria e Contabilidade e Congresso Anpcont 160

Analisando-se a Tabela 13, é possível observar que todas as correlações calculadas são positivas e significativas ( $\mathrm{p}$-valor $<0,05$ ).

Tabela 14 - Teste t de Student para comparar as médias de participantes no período dos três eventos

\begin{tabular}{c|c|c|c|c|c|c}
\hline Geral & Média & $\mathrm{N}$ & Desvio Padrão & $t$ & gl & P-valor \\
\cline { 1 - 4 } Mulheres & 73,07 & 15 & 25,789 & \multirow{2}{*}{$-6,364$} & \multirow{2}{*}{14} & 0,000 \\
\hline Homens & 163,2 & 15 & 48,409 & \\
\hline
\end{tabular}

Fonte: Dados da pesquisa (2009).

O teste $t$ para o conjunto dos eventos confirma a grande e significativa diferença entre as participações de homens e mulheres, indicando maior participação de homens.

\subsection{Autoras com maior quantidade de artigos nos eventos analisados}

Os dados coletados possibilitaram identificar os autores dos artigos publicados nos eventos em todos os períodos. Com esses dados, observou-se a quantidade de autoras nos três grupos de eventos analisados: 543 mulheres distribuídas em 755 artigos de autoria mista ou exclusivamente feminina.

$\mathrm{Na}$ pesquisa, foi possível identificar as pesquisadoras com maiores quantidades de artigos apresentados nos eventos analisados durante o período de 2004 a 2009. O Quadro 1 evidencia as três autoras com maior quantidade de artigos nos eventos analisados.

\begin{tabular}{|l|l|}
\hline \multicolumn{1}{|c|}{ Nome } & \multicolumn{1}{c|}{ Vínculo institucional atual } \\
\hline Ilse Maria Beuren & Fundação Universidade Regional de Blumenau - FURB (Santa Catarina) \\
\hline Maisa de Souza Ribeiro & $\begin{array}{l}\text { Faculdade de Economia, Administração e Contabilidade de Ribeirão Preto } \\
\text { - Universidade de São Paulo (São Paulo) }\end{array}$ \\
\hline Maria Thereza Pompa Antunes & Universidade Presbiteriana Mackenzie (São Paulo) \\
\hline
\end{tabular}

Quadro 1 - Autoras com maior quantidade de artigos (ordem alfabética) no período 2004 a 2009 Fonte: Dados da pesquisa (2009).

Essa lista de nomes corrobora os resultados apresentados na Tabela 1, segundo a qual se concentram mais nas regiões Sudeste e Sul os artigos publicados com a participação de mulheres.

\section{CONCLUSÃO}

O estudo apresentou dados sobre a participação feminina na produção científica em contabilidade publicada nos anais do Encontro da ANPAD e do Congresso USP de Controladoria e Contabilidade, ambos nos períodos de 2004 a 2009, assim como nos do Congresso da ANPCONT, no período de 2007 a 2009.

Os resultados apontam para uma participação expressiva de pesquisadoras das regiões Sudeste e Sul nos trabalhos publicados nos anais dos eventos. Dos 1.294 artigos analisados, 658 tiveram a participação de pesquisadoras da região Sudeste, enquanto 308 de autoras da região Sul. Constatou-se ainda a participação feminina em 755 artigos do total de artigos analisados, compreendendo 97 de autoria exclusivamente feminina e 658 de autoria mista.

A participação feminina em relação ao total de autores teve comportamento similar 
nos três grupos de eventos para os períodos analisados. O comportamento do gênero feminino assemelha-se ao do total de autores dos eventos, ou seja, um aumento na quantidade total de autores refletiu também em uma elevação na participação de pesquisadoras, mesmo que em proporções diferentes.

Realizados os testes de correlação, em todos os casos foram obtidos coeficientes de correlação positivos, embora nem todos tenham sido significativos, talvez por se tratar de um curto período de análise. Já os testes de comparação de médias comprovaram que a diferença média de participantes por gênero é grande e significativa.

Merece especial destaque a identificação das três autoras que registraram as maiores quantidades de artigos publicados nos eventos analisados: Ilse Maria Beuren, Maisa de Souza Ribeiro e Maria Thereza Pompa Antunes.

Conclui-se que a participação feminina na produção científica, no campo contábil, publicada nos eventos analisados, é significativamente pequena em relação à participação de autores do gênero masculino e costuma acompanhar o comportamento da quantidade total de autores, sofrendo uma queda nos últimos anos nos eventos da USP e da ANPAD e um aumento no Congresso da ANPCONT.

Ressalta-se que apesar do crescimento da participação da mulher no mercado de trabalho e da sua luta por igualdade de direitos e condições, sugerindo que a diferença entre homens e mulheres vem se tornando menos perceptível ao longo dos anos, o estudo revelou situação contrária para a participação feminina na produção científica da Contabilidade publicada nos eventos analisados.

Considerando-se a importância de dados sobre a pesquisa científica para o desenvolvimento da ciência, sugere-se ampliar o estudo com vistas a se determinar, dentre outros aspectos, a produção científica de áreas específicas do campo contábil e o perfil de pesquisadores, independentemente do gênero dos autores, abrangendo ainda outros veículos de divulgação como fonte de pesquisa, como, por exemplo, os periódicos científicos.

\section{REFERENCIAS}

ALVARADO. Rubén Urbizagástegui. A Lei de Lotka na bibliometria brasileira. Revista IBICT Brasília, v. 31, n. 2, p. 14-20, maio/ago. 2002. Disponível em $<$ http://revista.ibict.br/index. php/ciinf/article/viewFile/141/121> Acesso em abr de 2010.

ALVARENGA, Lídia. Bibliometria e arqueologia do saber de Michel Foucault: traços de identidade teórico-metodológica. Ciência da Informação. vol.27 n.3 Brasilia Set. 1998. Disponívelem<http:/www.scielo.br/scielo.php?pid=S0100-19651998000300002\&script=sci arttext\&tlng=in $>$ Acesso em abr de 2010.

BANDEIRA, Lourdes. A contribuição da crítica feminista à ciência. Revista Estudos Feministas v.16 n.1 Florianópolis Jan/Abr 2008. Disponível em < http://www.scielo.br/scielo. php?pid=S0104-026X2008000100020\&script=sci_arttext $>$ Acesso em maio de 2011.

BLAU, F. Trends in the Well-Being of American Women. 1970-1005. NBER Working Paper. 6206. October. 1997.

BRAGA, Josué P.; CRUZ, Claudia F da.; OLIVEIRA, José Renato Sena. Pesquisa contábil no Nordeste: um estudo bibliométrico da produção científica apresentada no Encontro Regional 
de Estudantes de Ciências Contábeis. In: CONGRESSO USP DE CONTROLADORIA E CONTABILIDADE; 7. São Paulo. Anais.. São Paulo: FEA/USP, 2007.

BUFREM, Leilah. PRATES, Yara. O saber científico registrado e as práticas de mensuração da informação. Ciência da Informação, vol.34 no.2. Brasília, Maio/Ago. 2005. Disponível em $<$ http://www.scielo.br/scielo.php?script=sci_arttext\&pid=S0100-19652005000200002\&lng= en\&nrm=iso\&tlng=pt $>$ Acesso em abr de 2010.

BRUSCHINI, Cristina; PUPPIN, Andréa Brandão. Trabalho de mulheres executivas no Brasil no final do século XX. Cadernos Pesquisa, v. 34, n. 121, São Paulo, jan./abr. 2004.

CAMPOS, M. Conceitos atuais em bibliometria. Arquivos brasileiros de Oftalmologia, São Paulo, v. 66, p. 1-22, 2003. Disponível em: http://www.abonet.com.br/abo/666s/edit07.pdf. Acesso em: abr 2010.

CHAMON, Magda. Trajetória de Feminização do Magistério: ambiguidades e conflitos. BH: Ed. Autêntica, 2005.

CNPQ - CONSELHO NACIONAL DE DESENVOLVIMENTO CIENTÍFICO E TECNOLÓGICO. Estatísticas e Indicadores do Fomento: Quantitativos de bolsas. Disponível em http://www.cnpq.br/estatisticas/bolsas/sexo.htm Acesso em maio de 2011.

DEC-UFCG DEPARTAMENTO DE ENGENHARIA CIVIL DA UNIVERSIDADE FEDERAL DE CAMPINA GRANDE. Lista dos Ganhadores dos Prêmios Nobel de Física. Disponível em: < http://www.dec.ufcg.edu.br/biografias/RolNobF5.htm>1. Acesso em maio de 2011

. Lista dos Ganhadores dos Prêmios Nobel de Economia. Disponível em http://www.

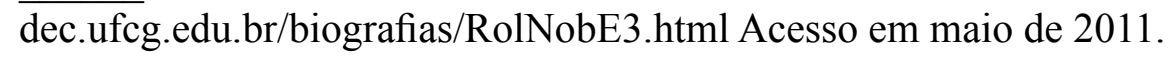

ESTEBANEZ, Maria Elina. As mulheres na ciência regional: diagnóstico e estratégias para a igualdade. ComCiênca, n. 50. Disponível em: <http:/www.comciencia.br/reportagens/ mulheres/10.shtml>. Acesso em: jan. 2010.

FREZATTI, Fábio; BORBA, José Alonso. Análise dos traços de tendência de uma amostra das revistas científicas da área de contabilidade publicadas na língua inglesa. Caderno de Estudos. São Paulo, v. 13, n. 24, p. 50-78, jul/dez 2000.

GUEDES, Vânia L S. BORSCHIVER, Suzana. Bibliometria: uma ferramenta estatística para a gestão da informação e do conhecimento, em sistemas de informação, de comunicação e de avaliação científica e tecnológica. In CINFORM - ENCONTRO NACIONAL DE CIÊNCIA DA INFORMAÇÃO, VI. Anais.. Salvador: UFBA, 2005.

HAYASHI, Maria Cristina Piumbato Innocentini et al. Indicadores da participação feminina em Ciência e Tecnologia. Revista Transformação. Vol.19 n.2 Campinas, 2007. Disponível em http://revistas.puc-campinas.edu.br/transinfo/viewarticle.php?id=258

LETA, Jacqueline. As mulheres na ciência brasileira: crescimento, contrastes e um perfil de sucesso. Estudos Avançados vol.17 n.49 São Paulo. Set/Dec. 2003. Disponível em < http:// www.scielo.br/scielo.php?pid $=\mathrm{S} 0103-0142003000300016 \&$ script $=$ sci_arttext $>$ Acesso em mai. 2011

LOPES, Maria Margaret. Gênero e ciências no país: exceções à regra? ComCiência, n. 50 Dezembro/Janeiro 2003. Disponível em: $<$ http://www.comciencia.br/reportagens/mulheres/01. shtml>. Acesso em: dez 2009.

MACHADO, Ana Flávia, OLIVEIRA, Ana Maria Hermeto Camilo de e WAJNMAN, Simone. Sexo frágil? Evidências sobre a inserção da mulher no mercado de trabalho brasileiro. Série estudos do trabalho, Coletânea Gelre. São Paulo: Organização Gelre, 2005. 
MACHADO, Raymundo das Neves. Análise cinetométrica dos estudos bibliométricos em periódicos da área de biblioteconomia e ciência da informação (1990-2005). Perspectiva em Ciências da Informação. Vol 12 n. 3 p. 2-20, set/dez 2007.

MARTINS, Gilberto de A. Considerações sobre os doze anos do Caderno de Estudos. Revista Contabilidade \& Finanças - USP. São Paulo, n. 30, p. 81-88, set/dez 2002.

MATOS, Raquel S. MACHADO, Ana Flávia, Diferencial de rendimentos por cor e sexo no Brasil (1987 - 2001). Econômica, Rio de Janeiro, v. 8, n.1, junho, 2006.

OLIVEIRA, Katya Luciane de et al. Produção científica em avaliação psicológica no contexto escolar. Psicologia Escolar e Educacional, v. 11, n. 2, Campinas, dez. 2007.

OLIVEIRA, Marcelle Colares. Análise do conteúdo e da forma dos periódicos nacionais de contabilidade. Tese (Doutorado em Controladoria e Contabilidade). FEA/USP, São Paulo, 2001.

RICCIO, Edson Luiz; CARASTAN, Jacira Tudora; SAKATA, Marici Cristine Gramacho. Accounting research in brazilian universities: 1962-1999. Caderno de Estudos. São Paulo, v. 11, n. 22, p. 35-44, set/dez 1999.

ROLEMBERG, Fúlvia. Educação formal, mulher e gênero no Brasil contemporâneo. Estudos Feministas, v. 9, n. 2, 2001, p. 521-527.

SAINERO, Gloria Carrizo. Toward a concept of bibliometrics. Madrid: Universidad Carlos III. Disponível em

<http://www.ucm.es/info/multidoc/publicaciones/journal/pdf/bibliometria-eng.pdf $>$. Acesso em abr. 2010.

SANTOS, Vívian Matias dos. A carreira científica é igualmente competitiva para mulheres e homens? Revista Espaço Acadêmico n. 80, jan.2008.

SOARES, Thereza Amélia. Mulheres em Ciência e Tecnologia: ascensão limitada. Química Nova, Vol. 24, n. 2, p.281-285, Recife, 2001. Disponível em http://www.scielo.br/pdf/\%0D/qn/ v24n2/4292.pdf Acesso em Maio de 2011

TIETZ, Wendy M. Women and men in accounting textbooks: exploring the hidden curriculum. Accounting Education, v. 22, n. 3, August 2007, p. 459-480.

VANTI, N. A. P. Da bibliometria à webometria: uma exploração conceitual dos mecanismos utilizados para medir o registro da informação e a difusão do conhecimento. Ciência da Informação, v. 31, n. 2, maio/ago. 2002.

VELHO, Lea. PROCHAZKA, Maria Viviana. Mulheres na ciência: no que o mundo da ciência difere dos outros mundos?. ComCiência, Campinas, Brasil, 10 dez. 2003. Disponível em < http://www.comciencia.br/reportagens/mulheres/09.shtml> Acesso em Jan de 2010.

VELHO, Lea; LEON, Elena. A construção social da produção científica por mulheres. Estudos Avançados, v. 17, n. 49. São Paulo, Sept./Dec. 2003. Disponível em: <http://www.scielo.br/ scielo.php?pid=S0103-0142003000300016\&script=sci_arttext $>$. Acesso em: jan. 2010.

VIGILANTE, Barbara. Women at full throttle. Journal of Accountancy, October 2005, p. 77. 


\section{ENDEREÇO DOS AUTORES:}

\section{Márcia Martins Mendes De Luca}

Universidade Federal do Ceará - Faculdade de Economia, Administração, Atuária, Contabilidade e Secretariado Executivo / Departamento de Contabilidade.

Avenida da Universidade, 2431 Benfica

Fortaleza, CE - Brasil

60020-180

\section{Carlos Adriano Santos Gomes}

Universidade Federal do Ceará - Faculdade de Economia, Administração, Atuária, Contabilidade e Secretariado Executivo / Departamento de Contabilidade.

Avenida da Universidade, 2431 Benfica

Fortaleza, CE - Brasil

60020-180

\section{Denise Maria Moreira Chagas Corrêa}

Universidade Federal do Ceará - Faculdade de Economia, Administração, Atuária, Contabilidade e Secretariado Executivo / Departamento de Contabilidade.

Avenida da Universidade, 2431 Benfica

Fortaleza, CE - Brasil

60020-180

\section{Sylvia Rejane Magalhães Domingos}

Universidade Federal do Ceará - Faculdade de Economia, Administração, Atuária, Contabilidade e Secretariado Executivo / Departamento de Contabilidade.

Avenida da Universidade, 2431 Benfica

Fortaleza, CE - Brasil

60020-180 